\title{
SOME NEW RESULTS ON IRRADIATION CHARACTERISTICS OF S YNTHETIC QUARTZ CRYSTALS AND THEIR APPLICATION TO RADIATION HARDENING
}

\author{
HARISH BAHADUR and R. PARSHAD, \\ National Physical Laboratory, \\ Hillside Road, New Delhi - 110 012, \\ India.
}

\begin{abstract}
The paper reports some new results on irradiation characteristics of synthetic quartz crystals and their application to radiation hardening. The present results show how the frequency shift in quartz crystals can be influenced by heat processing prior to irradiation and how this procedure can lead to radiation hardening for obtaining precise frequencies and time intervals from quartz oscillators in space.
\end{abstract}

In line with the thinking already proposed (H.Bahadur and R. Parshad, Proc. 12th PTTI Conference, pp.829849,1980 ) for explaining some of the irradiation characteristics of natural crystals, for the present work, it was assumed that the positive frequency shift in irradiated synthetic crystals is due to crystal imperfections. The crystal imperfections in synthetic crystals were sought to be removed by appropriate annealing (slow heating to $240^{\circ} \mathrm{C}$ followed by slow cooling). Different annealed crystals on irradiation gave either a negative frequency shift, thus simulating the behavior of natural crystals or almost a zero frequency shift. This result would be due to the positive frequency contribution of remanant crystal defects matching the negative frequency contribution of the A-centers of the crystal lattice.

The experimental results indicate a new way of radiation hardening.

This work was supported in part by a Homi Bhabha Fellowship awarded to H. Bahadur. 


\section{INTRODUCTION}

By now, intense work ${ }^{1-37}$ on irradiation characteristics of natural and synthetic quartz crystals has been carried out. The main results are the following. For optically clear natural quartz crystals, $\gamma$-and $\mathrm{X}$-irradiation produce a negative frequency shift culminating in most cases to a saturation state for prolonged radiation doses. For synthetic crystals the results are more complex and varying. For unswept crystals of lower grade 8 , or premium $Q^{16}$, the frequency increases with the dose. For swept crystals of the lower grade, the frequency remains constant with irradiation dose while for the premium $Q$ crystals, the results are varying (frequency increase or constant) depending upon the nature and technique of sweeping 16 or a constancy of frequency followed by decrease ${ }^{18}$.

For natural crystals, investigations in this laboratory $28,36,37$ showed that on irradiation, while the optically clear quartz gave the frequency characteristics following the literature results (negative frequency shift), but for the non-optically clear quartz the initial decrease of frequency was followed by an increase. This increase can be so much as to have the new resonance frequency greater than the starting frequency before irradiation.

We were led to believe that the ensuing positive frequency shift (after the initial negative shift) was due to the role of crystal defects present in the non-optically clear natural quartz, these defects also producing the relative opacity of the crystals. That crystal defects were present in such crystals was also adduced by results of investigations of EPR and thermoluminescence of these crystals 38However, these studies will not be discussed in the present paper.

Parallel with the role of defects in causing positive frequency shifts in natural crystals, it was thought that the overall positive frequency shift in synthetic crystals ${ }^{8}$ right from the time of irradiation was due to the greater density of defects present in such crystals (particularly in those produced at the time of Capone et.al.'s publication: Ref.8). The above thinking led us to the attempt of removing or decreasing the crystal defects by appropriate annealing before subjecting the crystal to $\gamma$-irradiation. The results have been rewarding and are detailed below. As would be seen, the results have not only fundamental interest but also indicate a new way of radiation hardening so desirable for use of crystals in satellite-borne frequency standards and other associated applications. 
The various synthetic crystal AT-cut resonators studied were drawn from both unswept and swept materials and oscillated in different frequency regions such as $1,3.5$ and $5 \mathrm{MHz}$. Swept crystals were Sawyer material and their sweeping was done at Sandia Laboratories, Albuquerque, NM. The unswept synthetic crystal resonators were assembled by Andhra Electronics, India. The resonators were used as the frequency determining elements in a self-oscillating modified Colpitts oscillator circuit. The crystals were $\gamma$-irradiated in steps from a ${ }^{60}$ Co source to different cumulative doses.

At the outset, before giving results for individual crystals, it should be stated that all the crystals, swept and unswept, gave on irradiation an initial frequency instability before the frequencies took up steady values. In this paper, the experimental results about only the steady frequency drifts will be described and discussed.

In the following are given the experimental results for the swept and unswept crystals separately. The studies on the swept crystals were done with the aim to effectively judge the results on the unswept synthetic crystals, all subjected to the same irradiation environment.

\section{Swept Synthetic Crystals}

Two swept resonators (designated as Resonators I and II) were operated in their third overtone in the frequency region of $3 \mathrm{MHz}$. Figures 1 and 2 represent the irradiation results. It can be observed that the steady frequency following the initial instability is unchanged as a result of irradiation.

Unswept Synthetic Crystals

The experimental results for unswept crystal resonators designated as Resonators III, IV and $V$ are given in tables I to III. As can be seen from the tables, for all the resonators the post-irradiation frequencies, following the literature results, were greater than those of the virgin crystals, the frequencies showing a saturation for extended doses. At this stage, the synthetic crystals already irradiated were annealed. In the annealing procedure, the resonators III, IV and $V$ were gradually heated to a maximum temperature of $240^{\circ} \mathrm{C}$ in a thermostat. They were kept at this temperature for a few hours $(\sim 5 \mathrm{hrs})$ and were subsequently cooled slowly at the rate of about $5^{\circ} \mathrm{C} / \mathrm{hr}$ to room temperature. The annealing process would, of course, also fully or partially bleach the crystals. It was interesting to observe that the resonance frequencies of the annealed crystals were lower than those of the original virgin crystals. 


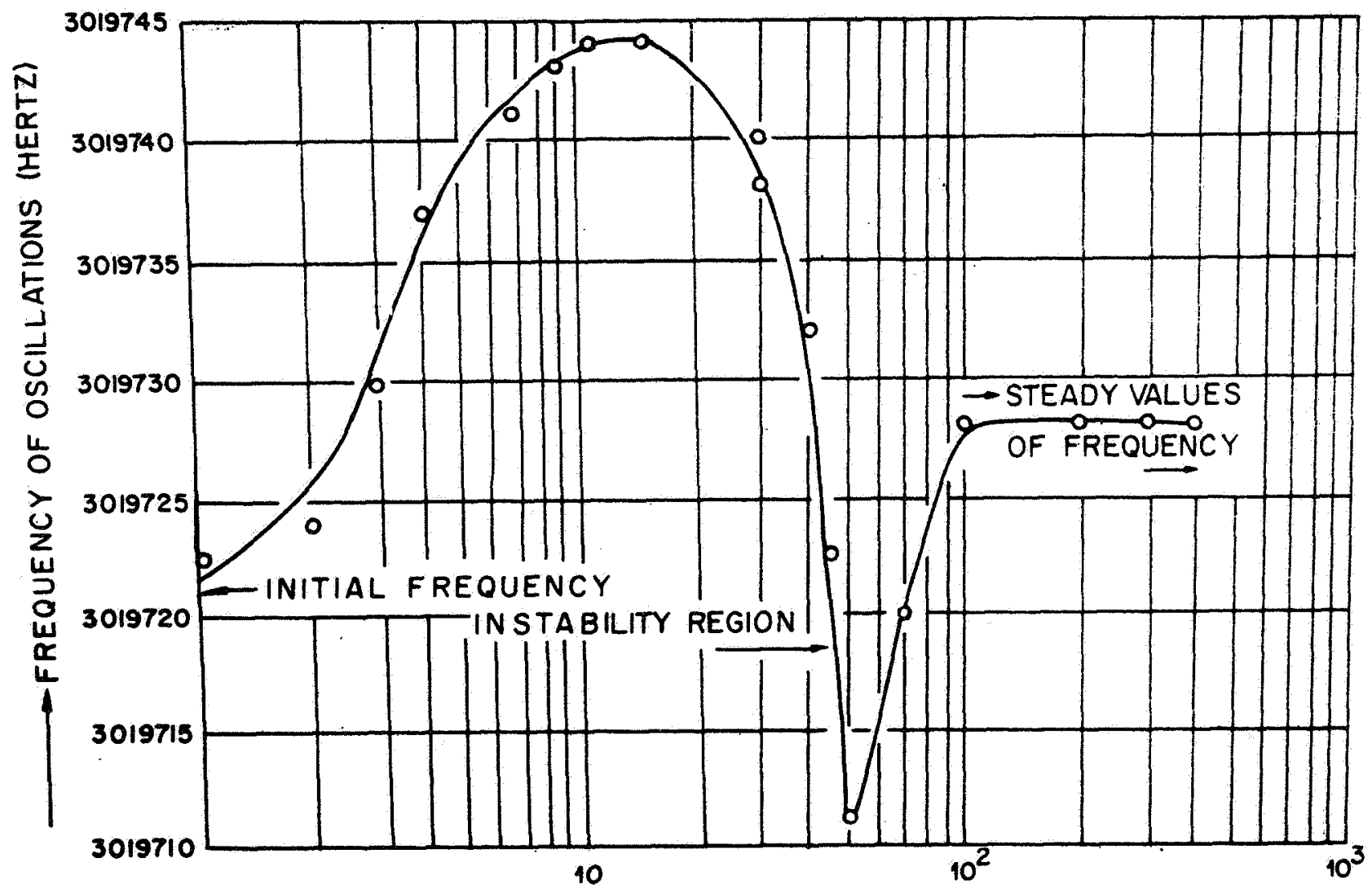

$\longrightarrow$ TIME IN MINUTES

Fig. 1 Post-irradiation frequency characteristic of a swept synthetic quartz resonator after irradiation by a dose of 1.5 MRads of $\gamma$-rays using $60^{\mathrm{Co}}$. The crystal is designated as resonator I in the text. 

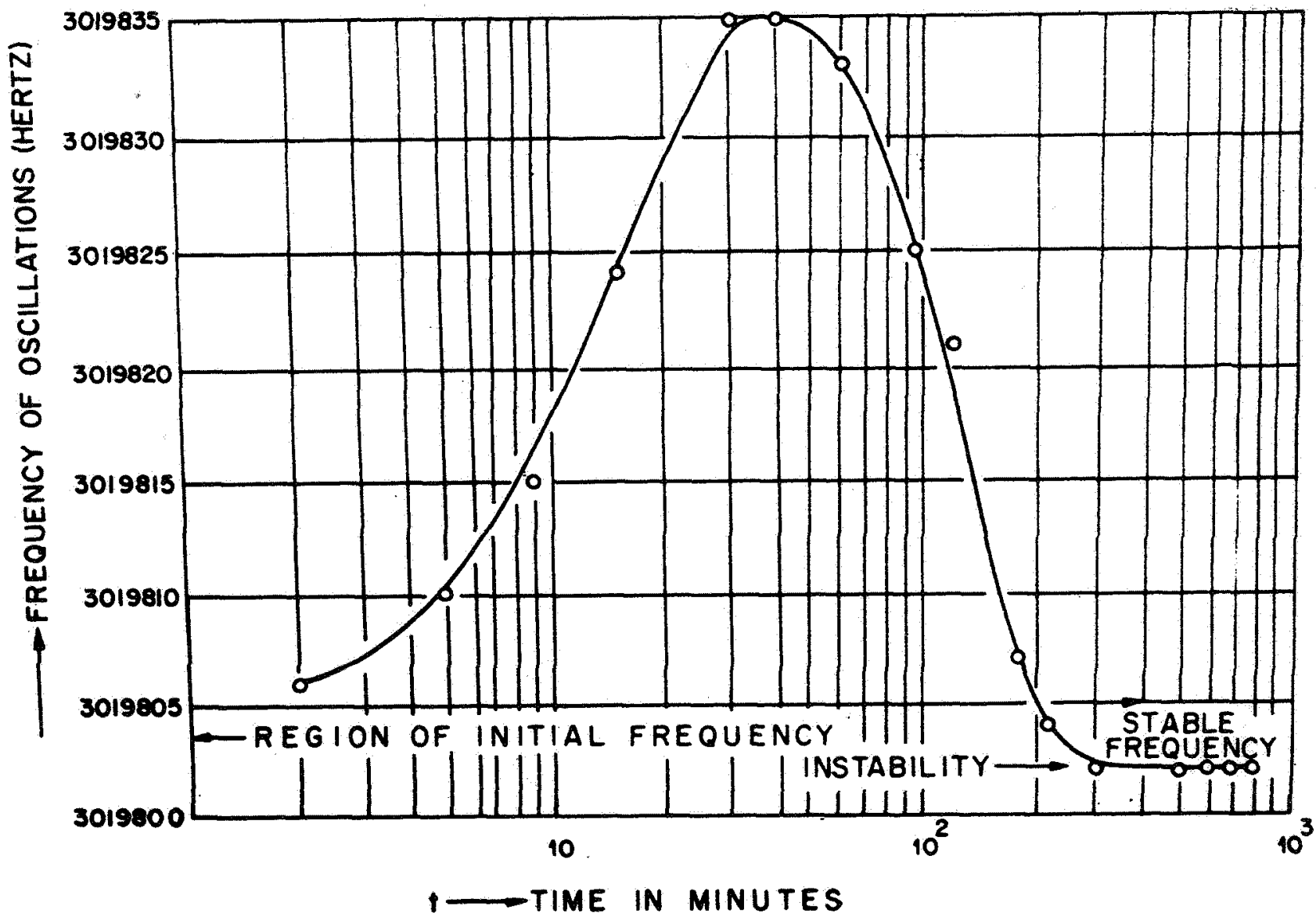

Fig. 2 Post-irradiation frequency characteric of a swept synthetic quartz resonator after irradiation by a dose of 1.5 MRads of $\boldsymbol{\gamma}$-rays using $60^{\mathrm{Co}}$. The crystal is designated as Resonator II in the text. 


\section{TABLE - I}

Frequency behavior of a 5-MHz (unswept) synthetic quartz crystal (Resonator III) on Y-irradiation.

Virgin crystal frequency $=5000217 \mathrm{~Hz}$.

\begin{tabular}{ccc}
\hline Dose & Steady frequency & Steady frequency offset \\
\hline 25 kRads & $5000253 \mathrm{~Hz}$ & $+36 \mathrm{~Hz}$ \\
50 kRads & $5000268 \mathrm{~Hz}$ & $+51 \mathrm{~Hz}$ \\
$100 \cdot$ kRads & $5000270 \mathrm{~Hz}$ & $+53 \mathrm{~Hz}$ \\
200 kRads & $5000273 \mathrm{~Hz}$ & $+56 \mathrm{~Hz}$ \\
\hline
\end{tabular}

At this stage the crystal was annealed. Frequency of annealed crystal was $4999792 \mathrm{~Hz}(\sim 480 \mathrm{~Hz}$ lower than the frequency of the virgin crystal). Further irradiation showed the following results.

\begin{tabular}{lll}
\hline Dose & Steady frequency & $\begin{array}{l}\text { Steady frequency offset } \\
\text { with respect to the } \\
\text { frequency of the an- } \\
\text { nealed crystal. }\end{array}$ \\
\hline 100 kRads & $4999775 \mathrm{~Hz}$ & $-17 \mathrm{~Hz}$ \\
$200 \mathrm{kRads}$ & $4999765 \mathrm{~Hz}$ & $-27 \mathrm{~Hz}$ \\
\hline
\end{tabular}


TABLE - II

Frequency behavior of a $3.5 \mathrm{MHz}$ (unswept) synthetic quartz crystal (Resonator IV) on $\varphi$-irradiation.

Virgin crystal frequency $=3500125 \mathrm{~Hz}$.

\begin{tabular}{|c|c|c|}
\hline Dose & steady frequency & Steady frequency offset \\
\hline 25 kRads & $3500153 \mathrm{~Hz}$ & $+14 \mathrm{~Hz}$ \\
\hline 50 kRads & $3500158 \mathrm{~Hz}$ & $+3 \dot{3} \mathrm{~Hz}$ \\
\hline $100 \mathrm{kRads}$ & $3500158 \mathrm{~Hz}$ & $+33 \mathrm{~Hz}$ \\
\hline 200 kRads & $3500160 \mathrm{~Hz}$ & $+35 \mathrm{~Hz}$ \\
\hline \multicolumn{3}{|c|}{$\begin{array}{l}\text { At this stage the crystal was annealed. Frequency of } \\
\text { annealed crystal was } 3500079 \mathrm{~Hz}(\sim 45 \mathrm{~Hz} \text { lower thar } \\
\text { the frequency of the virgin crystal). Further irradia- } \\
\text { tion showed the following results. }\end{array}$} \\
\hline Dose & Steady frequency & $\begin{array}{l}\text { Steady frequency offset } \\
\text { with respect to the } \\
\text { frequency of the an- } \\
\text { nealed crystal. }\end{array}$ \\
\hline $100 \mathrm{kRads}$ & $3500086 \mathrm{~Hz}$ & $+7 \mathrm{~Hz}$ \\
\hline 200 kRads & $3500084 \mathrm{~Hz}$ & $+5 \mathrm{~Hz}$ \\
\hline
\end{tabular}




\section{TABLE - III}

Frequency behavior of another $3.5 \mathrm{MHz}$ (unswept) synthetic quartz crystal (Resonator $V$ ) on $\mathcal{Y}$-irradiation.

Virgin crystal frequency $=3500087 \mathrm{~Hz}$.

\begin{tabular}{lcc}
\hline Dose & Steady frequency & Steady frequency offset \\
\hline 25 kRads & $3500107 \mathrm{~Hz}$ & $+20 \mathrm{~Hz}$ \\
50 kRads & $3500120 \mathrm{~Hz}$ & $+33 \mathrm{~Hz}$ \\
100 kRads & $3500123 \mathrm{~Hz}$ & $+36 \mathrm{~Hz}$ \\
2000 kRads & $3500123 \mathrm{~Hz}$ & $+36 \mathrm{~Hz}$ \\
\hline
\end{tabular}

At this stage the crystal was annealed. Frequency of the annealed crystal was $3500056 \mathrm{~Hz}(\sim 30 \mathrm{~Hz}$ lower than the frequency of the virgin crystal). Further irradiation showed the following results.

\begin{tabular}{lcl}
\hline Dose & Steady frequency & $\begin{array}{l}\text { Steady frequency offset } \\
\text { with respect to the } \\
\text { frequency of the annealed } \\
\text { crystal. }\end{array}$ \\
\hline 100 kRads & $3500062 \mathrm{~Hz}$ & $+6 \mathrm{~Hz}$ \\
$200 \mathrm{kRads}$ & $3500065 \mathrm{~Hz}$ & $+9 \mathrm{~Hz}$ \\
\hline
\end{tabular}


Regarding the irradiation cheracteristics of the annealed crystals, they changed rather drastically. For resonator III, the post-irradiation frequency was even less than the frequency of the bleached and annealed crystal (serving as the equivalent virgin crystal for the present series of experiments). Thus this crystal, in the way visualized by us, simulated the behavior of a natural crystal. Resonators IV and $V$ gave post-irradiation frequencies almost the same as they were before the second irradiation.

\section{DISCUSSION OF RESULTS}

The prominent results that stand out from our investigations are that on annealing the synthetic crystals the irradiation-frequency behavior changed characteristics rather drastically. In one resonator the characteristic became the same as of natural crystals (frequency decreasing with irradiation dose). The other two resonators studied showed almost a constant frequency characteristics (a residual positive frequency shift). The resonator with the negative frequency shift validates the assumption that the positive frequency shift due to irradiation of unannealed crystals is a result of crystal defects and therefore on removing or decreasing the defects on annealing, the frequency behavior would simulate that of the natural crystals. For these crystals, the negative frequency shift is of-course due to the contribution of the Acenters formed from their precursors, the so-called $\left[\mathrm{Al} / \mathrm{M}^{+}\right] \circ-$ centers 4 .

In the context of the above, the irradiation characteristics of the other resonators giving almost zero or residual positive frequency shift must be due to the positive frequency contribution of the remanant crystal defects (remaining after non-ideal annealing) almost matching the negative frequency shift:

Here, it may be of interest to observe that the frequencies of the annealed crystals (before second irradiation) were even less than those of the original virgin crystals. It has been shown earlier 38 that neutron-irradiated crystals and those subjected to high enough temperatures $\left(\sim 1000^{\circ} \mathrm{C}\right)$ and rapid enough cooling gave increased hardness and modulus of rigidity, all this leading to increase of resonance frequency. In the light of these results, the decrease of the observed resonance frequency by annealing indicates reduction or elimination of crystal imperfections, the premise on which the work of the present paper is based.

Apart from the fundamental interest of the investigations, the results have the immediate application in that more controlled annealing procedure would yield exact radiation hardening comparable to those of swept crystals (Figures 1 and 2) for satelliteborne frequency standards and other associated uses. 


\section{ACKNOWLEDGMENTS}

The authors appreciate the help of Dr. J.C. King of Sandia Laboratories, Albuquerque, NM in providing swept crystals for the present studies and wish to acknowledge the cooperation of Dr. M.M. Gupta, Mr. N.K.Ray and Mr. N.Kumar of Institute of Nuclear Medicine and Allied Sciences, New Delhi for various facets of irradiation.

REFERENCES

1. J.C. King, Proc. Intennat. Conf. Evaluation of Space Environment on Materials, Center Spatial de Toulouse, June 17-21, 1974.

2. C. Frondel, Amer. Mineralogist 30,416 (1945).

3. C. Frondel, Amer. Mineralogist 30,432 (1945).

4. J.C. King, Bell syst.tech.J. 38, 573 (1959).

5. R.A. Poll andS.L. Ridgway, IEEE Trans. Nuclear Sci. 13, 130 (1966).

6. D.B. Fraser, J. Appl.Phys. 35, 2913 (1963).

7. D.B. Fraser, Physical Acoustics, Ed. W.P. Mason, $\underline{5}$, Academic Press, New York, 59 (1968).

8. B.R. Capone, A. Kahan, R.N. Brown, and J.R. Buckmelter, IEEE Trans. Nucl. Sci., 17, 217 (1970):

9. T.M. Flanagan and T.F. Wrobel, IEEE Trans. Nuclear Sci. 16, 130 (1969).

10. E.P. EerNisse, Tech. Memo. Sandia Laboratories, SC-TM-70-417, July 1970

11. B.R. Capone, A. Kahan and B. Sawyer, Proc. Annual Frequency Control Symp., 25, US Army Electronics Command, NJ, 1971, p.109.

12. A. Kahan, B.R. Capone and R.N. Brown, Tech. Memo. LQ-16, Air Force Cambridge Res. Lab. , Bedford, Mass., March 16, 1973.

13. J.C. King (Ed.), Radiation Effects, 26, No.4 (1975).

14. T. Aoki, K. Norisawa, and M. Sakisaka, Japan. J. Appl. Phys. 15,2131 (1976).

15. ibid, 15, 749 (1976).

16. Paul Pellegrini, F. Euler, A. Kahan, T.M. Flanagan and T.F. Wrobel, IEEE Trans. Nucl. Sci. 25, 1267 (1978).

17. F. Euler, P. Ligor, A. Kahan, P. Pellegrini, T.M. Flanagan, and T.F. Wrobel, Proc. Annual Frequency Control Symp. , 32, US Army Electronics Command, Atlantic City, NJ, 1978, p.24.

18. H.G. Lipson, F. Euler and P.A. Ligor, Proc. Annual Frequency Control Symp. 33 , US Army Electronics Command, Atlantic City, NJ, 1979, p.122.

19. F. Euler, H.G. Lipson and P.A. Ligor, Proc. Annual Frequency Control Symp., 34, US Army Electronics Command, Atlantic City, NJ, 1980 .

20. J.C. King and H.H. Sander, IEEE TRans. Nucl. Sci. 19, 23, (1972).

21. E.F. Hartman and J.C. King, Proc. Annual Frequency Control Symp. 27, US Army Electronics Command, Atlantic City, NJ p. 124, (1973).

22. J.C. King and H.H. Sander, Radiation Effects 26, 203, (1975). 
23. E.F. Hartman and J.C. King, Radiation Effects, 26, 219 (1975).

24. J.C. King and H.H. Sander, IEEE Trans. Nucl. Sci. 20, 117 (1973).

25. Harish Bahadur and R. Parshad, Rev. Sci. Instrum. 51,1420 $(1980)$.

26. T.J. Young, D.R. Koehler and R.A. Adams, see (17) (p.34).

27. D.R. Koehler, see (18).

28. H. Bahadur and R. Parshad, Indian J. Phys. 53(A), 239 (1979).

29. J.C. King and D.B. Fraser, Proc. Annual Frequency Control Symp. 16, US Army Electronics Command, Atlantic City, NJ 1962, p. 7 .

30. F.B. Johnson and R.S. Pease, Phil. Mag. 45, 651 (1954).

31. J.C. King, Final Rep. Fundamental studies of the properties of Natural and Synthetic Quartz Crystals., Jan.15,1960 (Contract DA 36-039 Sc-64586).

32. H.G. Lipson, F. Euler and A.F. Armington, Proc. Annual Frequency Control Symposium, 32, US Army Electronics Command, NJ (1978), p.11.

33. David L. Griscom, Proc. Annual Frequency Control Symposium, 33, US Army Electronics Command, NJ, (1979).

34. L.E. Halliburton, M.E. Markes and J.J. Martin, Proc. Annual Frequency Control Symp. US Army Electronics Command, 34, (1980).

35. L.E. Halliburton, N. Koumavakalis, M.E. Markes and J.J. Martin, J. Appl. Phys. 52, (5), 3565 (1981) .

36. H. Bahadur and R. Parshad, , Phys. stat. solidi (a) 67,683 (1981).

37. H. Bahadur and́ R. Parshad, Proc. Second International Symp. Radiation Physics, Penang, Univ. Sains, Malaysia, 25-30 May, 1982 .

38. Harish Bahadur, "Investigations on Oscillating and Structural Characteristics of Quartz Crystals" Ph.D dissertation, Univ. of Delhi,Department of Physics, 1978. 


\section{QUESTIONS AND ANSWERS}

None for Paper \#31, Not Presented at PTTI 